See Article page XXX.

\section{Commentary: One cannot fix what one cannot see}

\author{
Kenza Rahmouni, MDCM, and \\ Fraser D. Rubens, MD, MSc, FACS, FRCSC
}

Surgeons have a simplistic way of classifying heart disease purely based on 2-dimensional imaging assessment of cardiac anatomy. As such, we embraced the definition of heart failure with preserved ejection fraction $(\mathrm{HFpEF})$ as the presence of heart failure symptoms with a left ventricular ejection fraction (LVEF) $\geq 50 \%$. However, a preserved LVEF can only exclude heart failure with reduced ejection fraction; it has no diagnostic role to prognosticate patients in the group of HFpEF. ${ }^{1}$ We are missing measurements of abnormal physiology and impaired ventricular relaxation to further understand the mechanisms in HFpEF. In this context, the Heart Failure Association Pretest Assessment, Echocardiography and Natriuretic Peptide, Functional Testing, Final Etiology (HFA-PEFF) score was developed as a novel diagnostic tool for HFpEF. ${ }^{1}$ This novel heart failure assessment tool incorporates not only anatomical criteria but also biochemical and functional variables.

In this issue of the Journal, Lee and colleagues ${ }^{2}$ used the HFA-PEFF score to stratify patients in a retrospective cohort study of 3593 patients with a preserved LVEF who underwent coronary artery bypass grafting. Thirty-day mortality was similar among those with and without HFpEF. However, the 5-year survival was significantly lower in the HFpEF group compared with the non-HFpEF group $(91.9 \%$ vs $97.0 \%$; hazard ratio, $2.41 ; 95 \%$ confidence interval, 1.29-4.50; $P=.006)$.

Another important finding from this study is that there was no significant improvement in early diastolic mitral

\footnotetext{
From the Division of Cardiac Surgery, University of Ottawa Heart Institute, Ottawa, Ontario, Canada.

Disclosures: The authors reported no conflicts of interest.

The Journal policy requires editors and reviewers to disclose conflicts of interest and to decline handling or reviewing manuscripts for which they may have a conflict of interest. The editors and reviewers of this article have no conflicts of interest.

Received for publication June 27, 2021; revisions received June 27, 2021; accepted for publication June 28, 2021.

Address for reprints: Fraser D. Rubens, MD, MSc, FACS, FRCSC, University of Ottawa Heart Institute, 40 Ruskin St, Ottawa, Ontario, Canada K1Y 4W7 (E-mail: FRubens@ottawaheart.ca).

J Thorac Cardiovasc Surg 2021; $\mathbf{\square}: 1-2$

0022-5223/ $\$ 36.00$

Copyright (c) 2021 by The American Association for Thoracic Surgery

https://doi.org/10.1016/j.jtcvs.2021.06.060
}

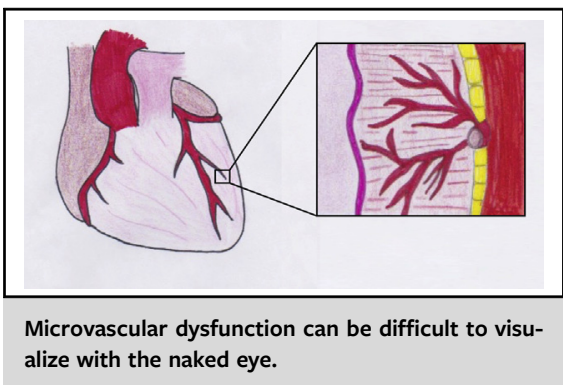

CENTRAL MESSAGE

Diastolic dysfunction in heart

failure with preserved ejection

fraction and coronary disease

may not be reversible with sur-

gical revascularization due to

ongoing microvascular disease

and inflammation.

annular velocity $\left(\mathrm{e}^{\prime}\right)$ or $\mathrm{LV}$ filling pressures $\left(\mathrm{E} / \mathrm{e}^{\prime}\right)$ at echocardiographic follow-up in the HFpEF group and indeterminate group. In other words, diastolic dysfunction in patients with coronary disease may not be reversible despite complete revascularization, even in the early stages of $\mathrm{HFpEF}$ before becoming detectable on diagnostic testing. This finding elicits the following question: is ventricular reverse remodeling possible in HFpEF?

Myocardial revascularization may not promote the same degree of ventricular reverse remodeling in HFpEF as it does in heart failure with reduced ejection fraction. This is possibly due to ongoing microvascular disease and myocardial inflammation in HFpEF, which cannot be addressed by macroscopic revascularization. ${ }^{2,3}$ It is therefore not surprising that Lee and associates report a greater longterm mortality and complication rate in patients with HFpEF after coronary artery bypass grafting compared with patients without HFpEF. These patients are also at greater risk of poor quality of life after surgical revascularization. ${ }^{4}$

In light of these mortality and quality of life outcomes, is it possible that surgical revascularization may not be as useful patients with HFpEF and coronary artery disease? Do these patients need some future alternative or concomitant therapy for microvascular disease to optimize their results? Perhaps our understanding of how to innovate to address this is limited by the inability of surgeons to see this therapy with our bare eyes. 


\section{References}

1. Pieske B, Tschöpe C, de Boer RA, Fraser AG, Anker SD, Donal E, et al. How to diagnose heart failure with preserved ejection fraction: the HFA-PEFF diagnostic algorithm: a consensus recommendation from the Heart Failure Association (HFA) of the European Society of Cardiology (ESC). Eur Heart J. 2019;40: 3297-317.

2. Lee SH, Choi KH, Song YB, Jeong DS, Yang JH, Kim WS, et al. Comprehensive assessment of heart failure in patients with preserved ejection fraction undergoing coronary bypass grafting. J Thorac Cardiovasc Surg. June 19, 2021 [Epub ahead of print].

3. Paulus WJ, Tschöpe C. A novel paradigm for heart failure with preserved ejection fraction: comorbidities drive myocardial dysfunction and remodeling through coronary microvascular endothelial inflammation. J Am Coll Cardiol. 2013;62: 263-71.

4. Sun LY, Tu JV, Lee DS, Beanlands RS, Ruel M, Austin PC, et al. Disability-free survival after coronary artery bypass grafting in women and men with heart failure. Open Heart. 2018;5:e00911. 